\title{
Initial Efforts toward Mission-Representative Imaging Surveys from Aerial Explorers
}

\author{
Greg Pisanich \\ Laura Plice \\ Corey Ippolito \\ QSS Group Inc \\ Computational Sciences Divịsion
}

\author{
Larry A. Young \\ Benton Lau
}

Army/NASA Rotorcraft Division

\author{
Pascal Lee \\ Mars \& SETI Institutes \\ NASA Ames Research Center \\ Moffett Field, CA 94035
}

\begin{abstract}
Numerous researchers have proposed the use of robotic aerial explorers to perform scientific investigation of planetary bodies in our solar system. One of the essential tasks for any aerial explorer is to be able to perform scientifically valuable imaging surveys. The focus of this paper is to discuss the challenges implicit in, and recent observations related to, acquiring mission-representative imaging data from a small fixed-wing UAV, acting as a surrogate planetary aerial explorer. This question of successfully performing aerial explorer surveys is also tied to other topics of technical investigation, including the development of unique bio-inspired technologies.
\end{abstract}

Keywords: Aerial imaging, Planetary explorer, UAV, Unmanned aerial vehicle

\section{INTRODUCTION}

The high-level of mobility, and unique observational perspective, afforded by aerial vehicles makes them potentially extremely valuable tools for conducting robotic planetary science missions. However, the potential of these aerial explorers is counterbalanced to some degree by high vehicle development costs, concern over achieving robust sustained flight in unknown or uncertain environments, and the potentially low scientific return-on-investment because of limited powered-flight endurance, and, in many cases, inability to safely land or takeoff to conduct multiple sorties.

The Intelligent Aerial Vehicle (IAV) project problem statement is therefore: 1. How to develop autonomy tools and vision-based systems to robustly fly planetary aerial vehicle missions, and 2. How to conduct high quality science (such as to search and find the subtle evidence of water and past or current life) from a low- to mid-altitude aerial survey (which in the case of a Mars airplane over Mars is also flying at high speed to maintain sufficient aircraft lift). Figure. 1 shows the contrast between an aerial view and the signs of life that exist below.
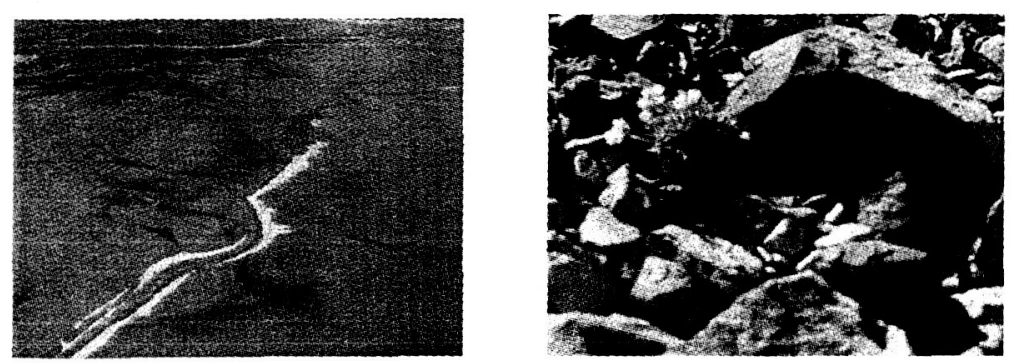

Figure 1. - The Challenge: Searching for subtle signs of life in a barren landscape from the air. 


\section{FIELD DEMONSTRATIONS}

The aerial survey imaging research conducted so far has focused around science field demonstrations using an assortment of aerial vehicles at Haughton Crater, Devon Island, Nunavut, Canada, a well-documented Mars-analog research site ${ }^{1}$. The key feature of the site is a $10 \mathrm{~km}$ diameter, 20 million year old impact crater. This terrain feature of interest, among others, is the reason it is of interest to planetary explorers.

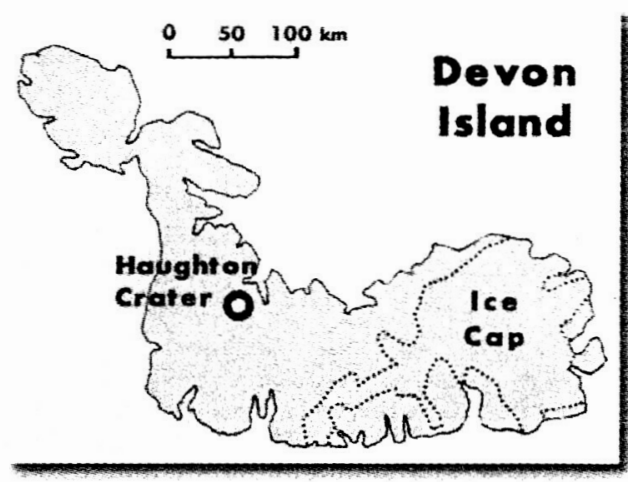

(a)
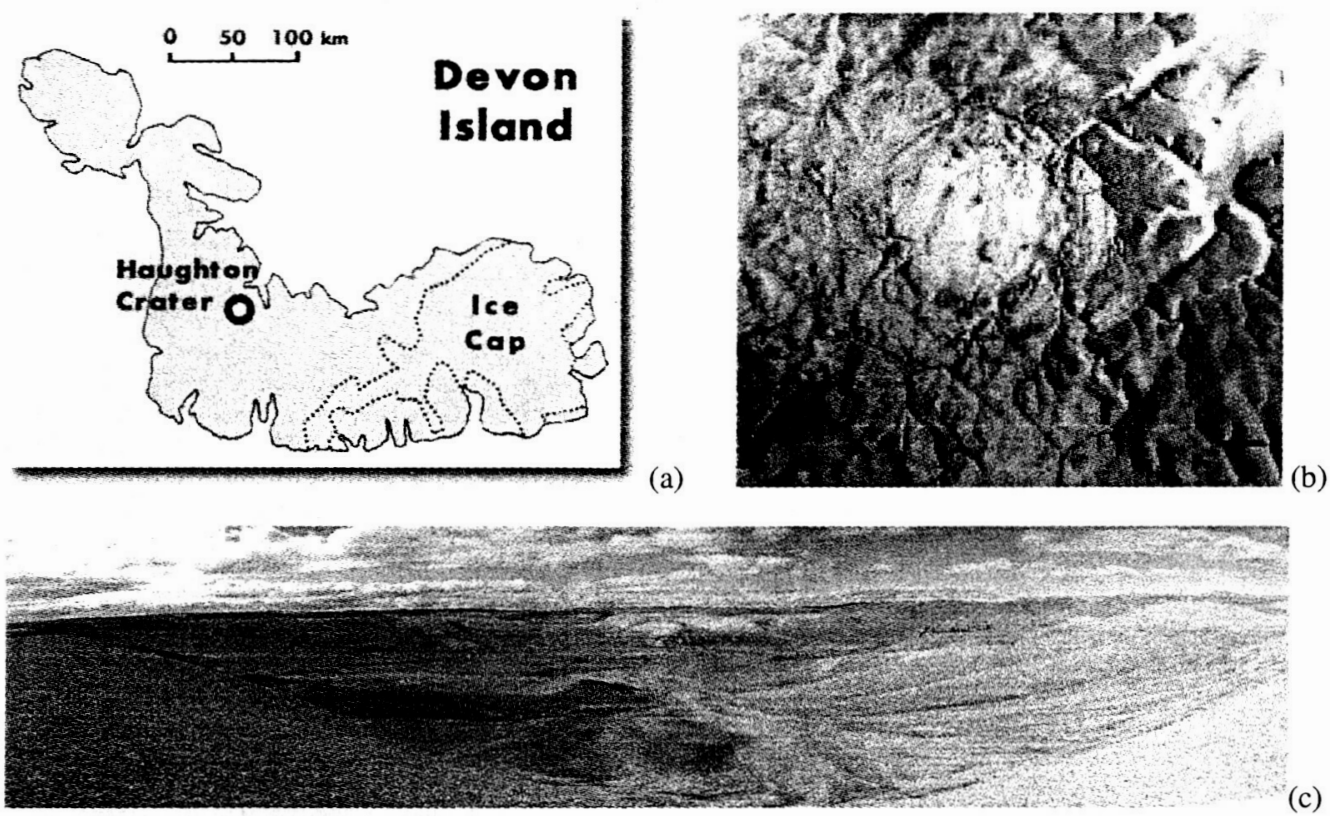

(c)

Figure 2. - Haughton Crater, Devon Island Mars-Analog Site (a) map, (b) satellite view, and (c) view from the ground (images courtesy of the Haughton Mars Project)

\subsection{Field season 2002}

An initial demonstration of aerial explorer flight at Haughton Crater was conducted in the summer of 2002. A small commercial UAV was taken to the Mars-analog site and flown over a number of geologically interesting stretches of terrain (Figure 3). The UAV was capable of being controlled from the ground via line-of-sight radio and flown through pre-programmed GPS waypoints. This initial demonstration was primarily for site familiarization purposes as well as acquiring imaging data to enable the development of vision-based navigation systems.
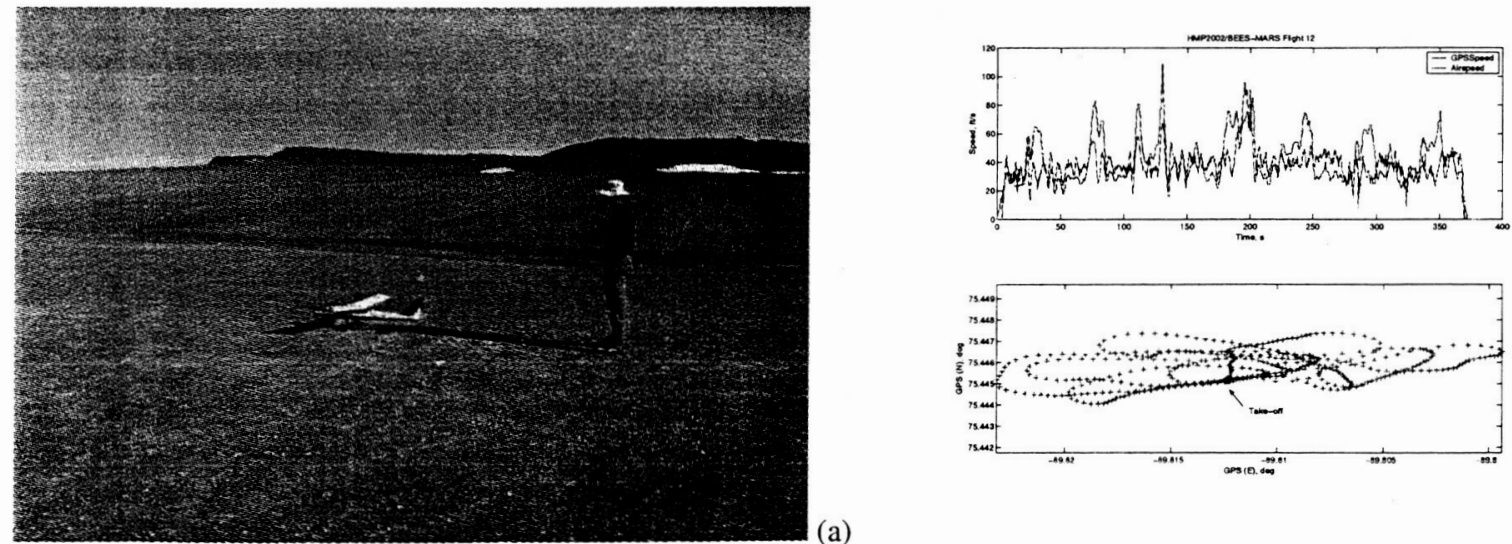

(a)

Figure 3. - Summer Field Demo 2002: (a) Micropilot UAV and (b) typical GPS telemetry from Haughton. 
A large digital aerial video set, in many cases with embedded GPS coordinates, was acquired over several geologically significant features. Important geological and astrobiological sites were imaged with UAV: example images included dry river beds (Figure 4.) and snowmelt water run-off on hillsides (Figure 5). In each of these cases, analogs with Mars terrain features of interest were established.
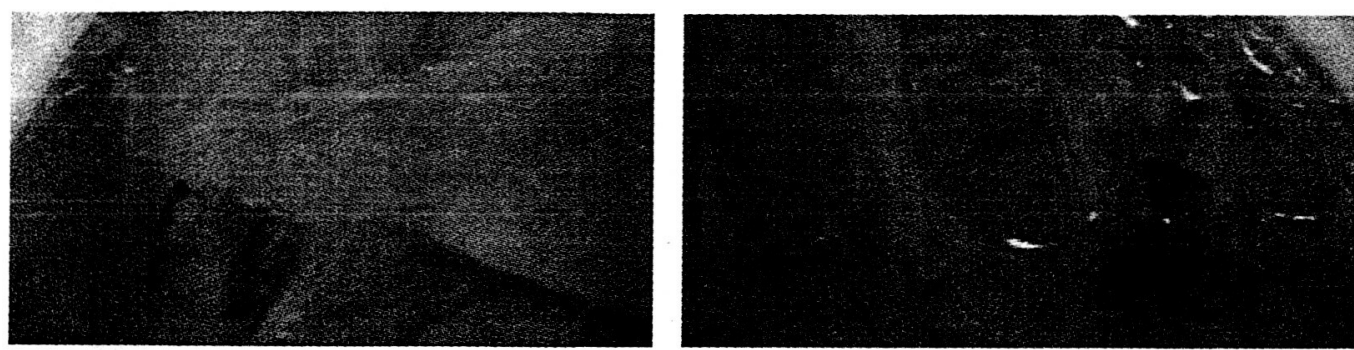

Figure 4. - Dry riverbed (panoramic image formed by tight banking turns - 0 and 180 deg. azimuth -- with UAV).
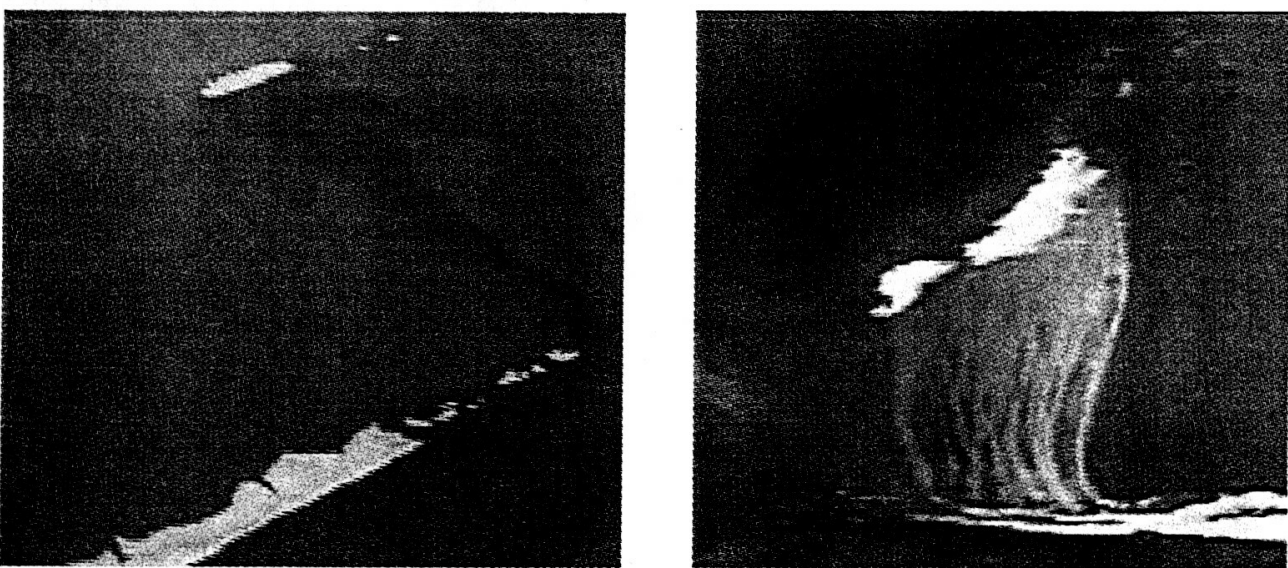

Figure 5. -- Examples of hillside water runoff from snow melt.

\subsection{Field season 2003}

Table 1 outlines the multiple objectives and overall test plan matrix of the Haughton 2003 field season. In particular, the 2003 flight-testing complemented and extended the work accomplished in the 2002 field season. For the 2003 season, a MLB "Bat" UAV with improved navigational and camera sensors was flown (Figure 6).

Table 1 - Test Plan Matrix

\begin{tabular}{|l|l|}
\hline Objective & Test Plan \\
\hline 1. Search \& Find Autonomy & $\begin{array}{l}\text { Assess satisfactory operation of UAV with GPS waypoint navigation. Reproduce, on an open } \\
\text { plain close to Base Camp, search and find scenario conducted at NASA Ames August 2002 }\end{array}$ \\
\hline $\begin{array}{l}\text { 2. Deriving Scale \& Feature } \\
\text { Information }\end{array}$ & $\begin{array}{l}\text { Fly a series of remote-piloted, or autonomous flights at 3 or more UAV altitudes }(100,200,400 \\
\text { ft) over the same terrain features. Post-process the images to derive a qualitative sense of the } \\
\text { effect of altitude on feature resolution, scale, and three-dimensional characteristics. }\end{array}$ \\
\hline 3. Assessing Impact of Perspective & $\begin{array}{l}\text { Perform three series of remote-piloted, or autonomous, flights over a common set of terrain } \\
\text { features of interest. First, fly alongside a range of hills at different altitudes, lateral offset } \\
\text { distances, and oblique angles. Second, approach hillsides with water-runoff features at various } \\
\text { oblique angles. Third, perform circling flight, at different altitudes, around discrete terrain } \\
\text { features such as rock formations and valley networks. }\end{array}$ \\
\hline 4. Ground Truth & $\begin{array}{l}\text { Perform a series of drop probe releases and post-process the data to assess the size and scale of } \\
\text { ground features during descent. }\end{array}$ \\
\hline
\end{tabular}




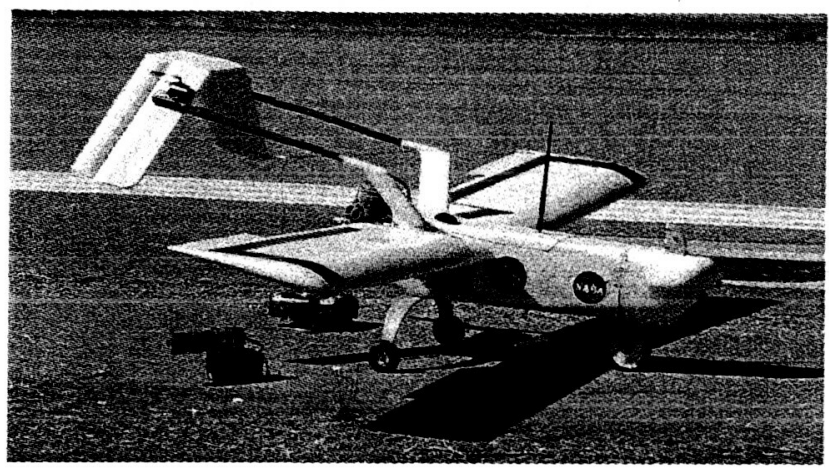

Figure 6 - MLB 'BAT' UAV used in 2003 Haughton season.

\section{TERRESTRIAL AND PLANETARY AERIAL SURVEYS}

It is important to consider the similarities and differences between aerial imaging surveys conducted by terrestrial UAVs and by future planetary aerial vehicle "explorers." Beyond the obvious differences in design features between terrestrial UAVs and planetary aerial vehicles, there are also operational differences, as well as differing levels of vehicle autonomy required.

Table 2 - Differences between Terrestrial and Planetary Aerial Explorer Imaging Surveys

\begin{tabular}{|c|c|c|}
\hline & Terrestrial & Planetary \\
\hline Survey Patterns & $\begin{array}{l}\text { Grid and/or Spiral Patterns; i.e. the ideal is } \\
\text { an exhaustive coverage of prescribed } \\
\text { search area. }\end{array}$ & $\begin{array}{l}\text { Bio-inspired search and find patterns: i.e. "fox and mouse," intelligent } \\
\text { random walk, follow the gradients, etc'. Alternatively, straight and level } \\
\text { flight paths (in preferred direction) may be employed for early missions. }\end{array}$ \\
\hline Navigation & GPS based. Magnetic compass. & $\begin{array}{l}\text { Non-GPS-based. Vision-system navigation via tracking of terrain } \\
\text { features of interest. Sun (or star, or planet) compass and horizon } \\
\text { tracking. Altimeter terrain following via simple heuristic rules or digital } \\
\text { maps. }\end{array}$ \\
\hline $\begin{array}{l}\text { Flight Speed and } \\
\text { Altitude }\end{array}$ & $\begin{array}{l}\text { Aircraft can fly low and slow if required. } \\
\text { Considerable is available flexibility in } \\
\text { tailoring speed and altitude to meet } \\
\text { mission and imaging requirements. } \\
\text { Portions of mission can be handed off to } \\
\text { other aerial vehicles, and imaging } \\
\text { platforms, if need be, to further optimize } \\
\text { the imagery return. }\end{array}$ & $\begin{array}{l}\text { In particular for Mars flyers, there is limited flexibility to tailor speed and } \\
\text { altitude as compared to terrestrial aerial vehicles. Mars aerial explorers } \\
\text { will have to fly fairly fast }(\text { Mach }>0.5) \text { in order to sustain adequate lift in } \\
\text { the thin atmosphere of Mars. This complicates imaging surveys for Mars } \\
\text { aerial explorers, i.e. acquiring high-resolution, blur-free, images while } \\
\text { flying at high speed, perhaps at low-altitude in somewhat uncertain } \\
\text { terrain. }\end{array}$ \\
\hline Flight Endurance & $\begin{array}{l}\text { Long endurance flights on the order of } \\
\text { tens of hours achievable; in-flight } \\
\text { refueling possible }\end{array}$ & $\begin{array}{l}\text { Most estimates of Mars flyers have endurances on the order of minutes to } \\
2-3 \text { hours at most. Similar flight endurances are likely for aerial } \\
\text { explorers for other planetary bodies, unless a means is devised to refuel } \\
\text { or recharge the vehicle in-flight, has the ability to take-off and land } \\
\text { (likely vertically), and/or is capable of performing dynamic and thermal } \\
\text { soaring for a portion of its flight. }\end{array}$ \\
\hline $\begin{array}{l}\text { Imagery \& Real- } \\
\text { time Data } \\
\text { Processing and } \\
\text { Handling }\end{array}$ & $\begin{array}{l}\text { High-resolution and multi-spectral data } \\
\text { can be transmitted from the aircraft via } \\
\text { high-bandwidth satellite relays or } \\
\text { transported back to the launch or recovery } \\
\text { site }\end{array}$ & $\begin{array}{l}\text { Post fight survivability (to be able to effect a "soft crash") leading to } \\
\text { periodic uplink of imagery data to orbiter or directly to Earth will be } \\
\text { required for the gigabytes of data acquired for an aerial explorer mission. }\end{array}$ \\
\hline Support Assets & $\begin{array}{l}\text { Satellite telecom. Ground stations. } \\
\text { Telecom and navigation relays. Launch } \\
\text { and recovery site assets. }\end{array}$ & $\begin{array}{l}\text { Only limited availability at best; addition of orbiter significantly increases } \\
\text { mission cost; pre-existing orbiter assets from earlier missions might be } \\
\text { available. }\end{array}$ \\
\hline Multiple Sorties & Yes. & $\begin{array}{l}\text { No - unless multiple aerial explorers are employed and/or explorers with } \\
\text { vertical lift (hover, vertical take-off and landing) capability are used. }\end{array}$ \\
\hline Robotic "Ecology" & $\begin{array}{l}\text { Can be flown as a single unit, or part of a } \\
\text { "system of systems" network }\end{array}$ & $\begin{array}{l}\text { It is a necessary, but not a sufficient, mission objective that an aerial } \\
\text { explorer perform high-quality aerial imaging surveys. It is likely that } \\
\text { such vehicles will have to release drop probes and other sensors (passive } \\
\text { as well as "intelligent"), as well as work in cooperation and coordination } \\
\text { with other robotics assets in a kind of "ecology." }\end{array}$ \\
\hline
\end{tabular}




\section{TERRAIN FEATURES OF INTEREST}

In conducting the aerial surveys of the Haughton Crater, Mars-analog site, it was essential to not only identify what needed to be accomplished in the fixed-wing UAV flight demonstrations. It was equally important to identify the areas for over-flight during the demonstrations that contained scientifically valuable terrain features of interest. Table 3 lists several of those key features.

Table 3. - Mars-Analog Features of Interest

\begin{tabular}{|c|c|c|}
\hline Feature & Location & Reason for Interest \\
\hline & Longitude, Latitude & \\
\hline Dry River Beds & $\begin{array}{l}\text { Launch site GPS Coordinates: } \\
\text { N } 75.389319 \text { W } 89.872469 \\
\text { Camera Angle } ~ 35 \text { Deg. } \\
\text { downward. }\end{array}$ & $\begin{array}{l}\text { Through telescopic and planetary probe evidence, Mars appears to } \\
\text { have had in the remote past, at least, periods where large bodies of } \\
\text { surface water and possibly massive flooding existed. The ability of } \\
\text { aerial explorers to identify ancient surface features indicative of the } \\
\text { existence of past water is paramount. }\end{array}$ \\
\hline $\begin{array}{llll}\text { Snow-Melt Water Run-off on } \\
\text { Hillsides }\end{array}$ & $\begin{array}{l}\text { N 75-26.135 W 89-51.605 } \\
\text { (Near Base Camp) } \\
\text { Camera angle } \sim 45 \text { Deg. } \\
\text { downward }\end{array}$ & $\begin{array}{l}\text { There is limited, and controversial evidence, that water run-off on the } \\
\text { rim of craters and hillsides on Mars may, even to this day, may be } \\
\text { occurring and forming features such as "gullies." One line of } \\
\text { thinking gaining acceptance among planetary scientists is that these } \\
\text { gullies are forming as a result of seasonal snowmelt run-off. Devon } \\
\text { Island has many examples of such snowmelt run-off features, and, } \\
\text { again, it is imperative that an aerial explorer be able to identify and } \\
\text { locate such features. }\end{array}$ \\
\hline "Fortress" Rock Formation & $\begin{array}{l}\text { N 75-.25.980 W 89-51.240 } \\
\text { Near Base Camp Runway. }\end{array}$ & $\begin{array}{l}\text { Isolated rock formation with considerable surface geological detail. } \\
\text { Excellent test case for extracting three-dimensional characteristics } \\
\text { from sequential aerial survey images. }\end{array}$ \\
\hline Hamilton-Sundstrand Rock & $\begin{array}{l}\text { N 75-26.765 W } 89-52.258 \\
\text { Located in the middle of Von } \\
\text { Braun Planitia. }\end{array}$ & $\begin{array}{l}\text { Excellent example of the "blue rock" planetary science scenario, } \\
\text { wherein tiny almost indistinguishable signs of evidence are found in a } \\
\text { wide expanse of barren sterile terrain. Almost unnoticed on the top of } \\
\text { the Hamilton-Sundstrand rock is a tiny patch of reddish orange arctic } \\
\text { flora. The rock itself is a lone formation in a wide barren plain. } \\
\text { Again, this is an excellent test case of finding discrete noteworthy } \\
\text { features - the rock itself and then even more subtlety the orange } \\
\text { lichen -- in nearly featureless aerial survey information. }\end{array}$ \\
\hline "Marine Peak" & N 75-26.826 W 89-54.225 & Marine Peak is an example of a hillside with snowmelt run-off. \\
\hline "Pete Conrad" Valley & N 75- $25.826 \mathrm{~W} 89-54.213$ & $\begin{array}{l}\text { A small valley network with noteworthy rock formation. An } \\
\text { excellent test case for extracting three-dimensional surface features } \\
\text { from aerial survey images. Additionally, this valley network reveals } \\
\text { several water flow features, including a modest riverbed with limited } \\
\text { snowmelt water flow on one side of the valley network. The steep } \\
\text { rock formations surrounding the Pete Conrad Valley illustrate an } \\
\text { important point about using aerial explorers to gain access to sites } \\
\text { with rugged terrain, as well as deriving unique viewpoints or } \\
\text { perspectives to analyze the terrain features of interest. }\end{array}$ \\
\hline
\end{tabular}

In the future, additional sites will hopefully be examined using over flights including: plains, canyons, valleys, gullies formed from snowmelt, Haughton crater itself, ejecta blocks, and sites of thermal vent water seepage.

\section{SEARCH AND FIND}

The first goal of the small, fixed-wing UAV field demonstrations conducted at the Haughton Crater, Devon Island site was to perform simulated aerial explorer "search and find" missions using bio-inspired search strategies and vehicle autonomy software based on "flight behavior" modeling ${ }^{2-4}$.

Beyond the broad scope of a Mars aerial vehicle mission which must, in large part, be the often-noted mantras of "follow the water" and "hunt for life," what exactly would an aerial explorer be looking for, and how would go about doing it? The answers to these questions have important implications as to the imaging approach taken for an aerial explorer. 
Testing at NASA Ames research Center and at the Haughton Crater Mars-analog site has focused around the use of bioinspired "search and find" flight behaviors and the use of a simple vision-system to recognize an "orange tarp" that provides a simple sensor trigger to define discovery of a terrain "feature of interest." As more sophisticated and lightweight vision-systems and sensors become available, they can be incorporated into the UAV flight behavior modeling. Figure 7 shows a generic grid pattern search strategy with the uplink and downlink interfaces required to search for a target (orange tarp) within the confines of Moffett Field Federal Airstrip. Upon discovery of the orange tarp (both during testing at Ames and at Haughton Crater) a small camera drop probe is deployed over the coordinates of the tarp (Figure 8.). Wireless video provides a means of acquiring ground truth of the feature of interest site, as well as enabling in a global sense the "calibration" of aerial imagery to the ground images.

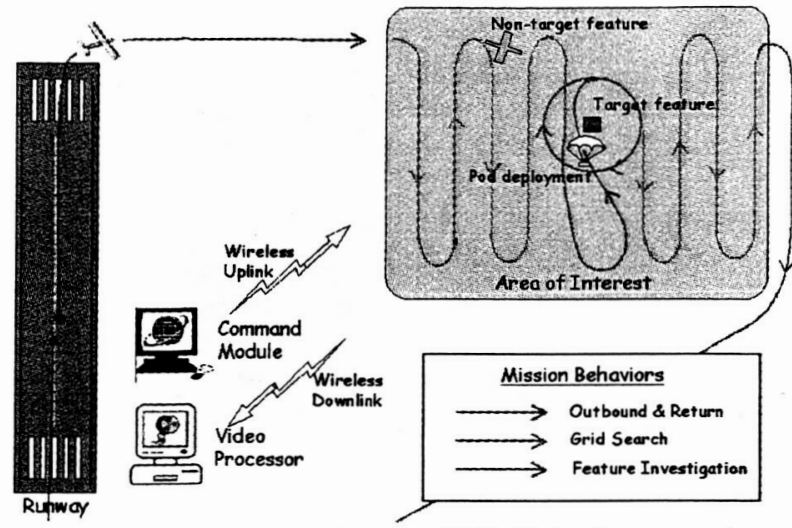

Figure 7. - Schematic of October 2002 flight demonstration.

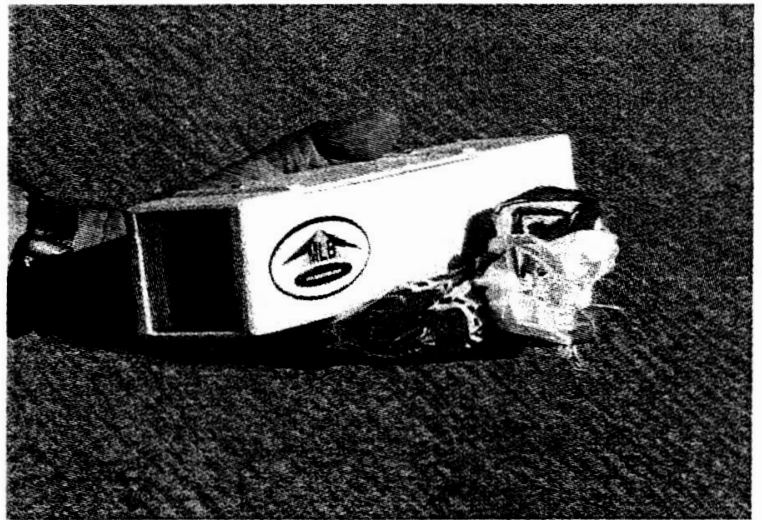

Figure 8. - Video drop pod and parachute.

The release of a camera drop probe (or other air-deployed sensor) is consistent with earlier work ${ }^{2-3}$ examining Mars aerial explorer mission scenarios in light of biological reproduction strategies found in nature. In effect, the release of the camera drop probe reflects analogously the dissemination strategy associated with the so-called $\mathrm{r} \& \mathrm{~K}$ survivorship types embodied by some living creatures.
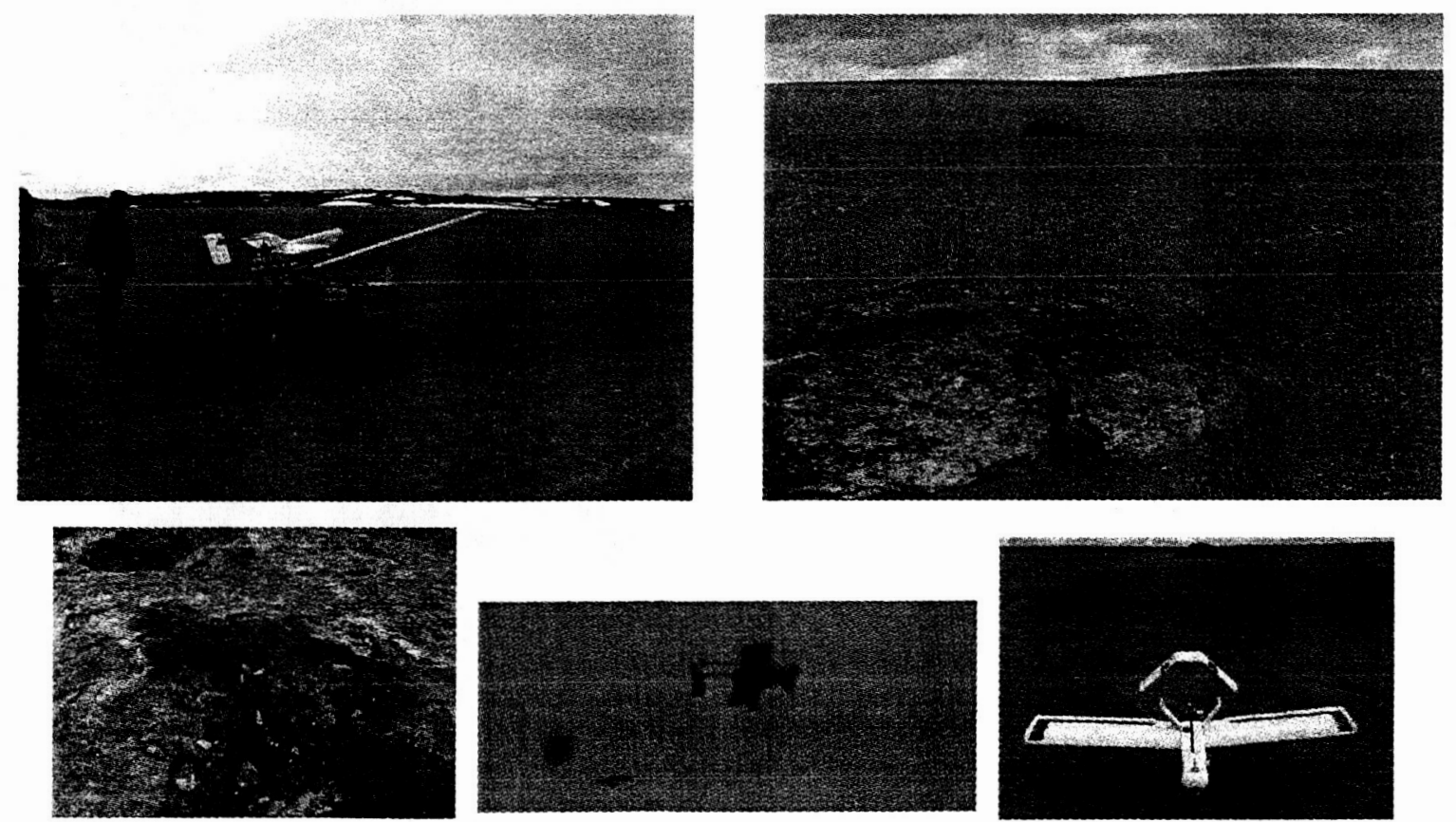

Figure 9. $-r$ \& K Mission Scenario Strategy Demonstration (Orange Tarp Analogous to Lichen on the Hamilton-Sundstrand rock located on the Von Braun Planitia). 


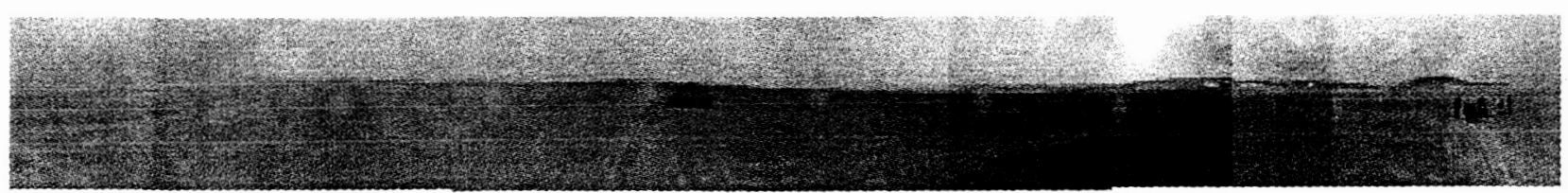

Figure 10. - Ground $\left(360^{\circ}\right)$ Panoramic Image of the Von Braun Planitia

In the case of the Devon Island demonstrations, a single drop probe is released over a terrain feature of interest (an orange tarp near the isolated Hamilton Sundstrand rock) that has active biological implications (existence of a small patch of orange colored lichen) in the middle of a largely barren and featureless Von Braun Planitia ("plain"). Figures 9 and 10 show images of the Haughton demonstration and flight environment.

\section{A QUESTION OF SCALE}

An image without context is nearly worthless in terms of scientific value. A field scientist, or planetary science researcher, needs to understand the scale and context in which the aerial image data were gathered. A key part of establishing the context of the aerial images is acquiring a qualitative, and ideally quantitative, sense of "ground truth" about the terrain over which the aerial vehicle is flying. Scientists establish ground truth at relatively accessible terrestrial sites by gathering photographic, spectral, and contact data (Figure 11).

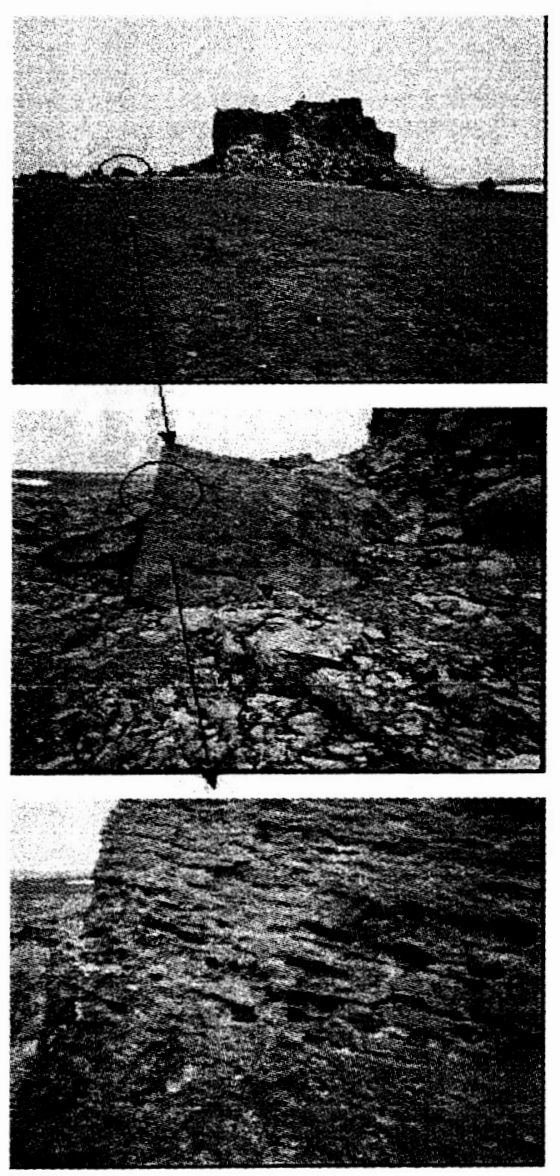

Fig 11. -- Several Different Scales of "Ground Truth" 
It is also important to ask how to perform good science while employing aerial explorers, whether for field science in extreme terrestrial environments or for planetary science missions. It is essential to complement aerial imaging data at low to moderate flight altitudes with "ground truth" images. Establishing ground truth from an aerial explorer on Mars is an entirely different challenge. One possible strategy, as previously applied, is the deployment of camera sensor drop probes from the aerial vehicle (Fig. 12). The two sets of images (from the aerial vehicle and from the drop probes) complement each other and provide a calibrated viewpoint of high value features of interest on the planetary surface (substituting if you will a geologist or biologist's eyes). This "calibration" will enable improved interpretation of surface images from the aerial survey imaging data, even for over-flight areas where drop probes are not released. Drop probes with wireless video cameras have been demonstrated numerous times at NASA Ames as well as the Haughton Crater.

Figure 12 is an illustrative set of images from a drop probe release near the Hamilton-Sundstrand rock located on an ancient dry lakebed in the middle of the Von Braun Planitia. The deployment of the drop probe was triggered by the recognition of the orange tarp located near the isolated boulder. The emergence of detail in the terrain features as the probe descends is notable in figure 12. The images from the drop probe also serve to illustrate several problems. First, as the probe lacked a swivel in the parachute rigging, there is a large amount of frame-by-frame rotation in the images. Second, as there was a significant steady crosswind at the drop probe release site, the probe traveled a considerable distance downwind its release - and the orange tarp. These problems can be corrected or accounted for in future generations of drop probes. Aerial explorers employing drop probes with cameras and other instruments remain a powerful combination that can provide an essential element of context and relative scale which is unavailable to aerial survey images alone.
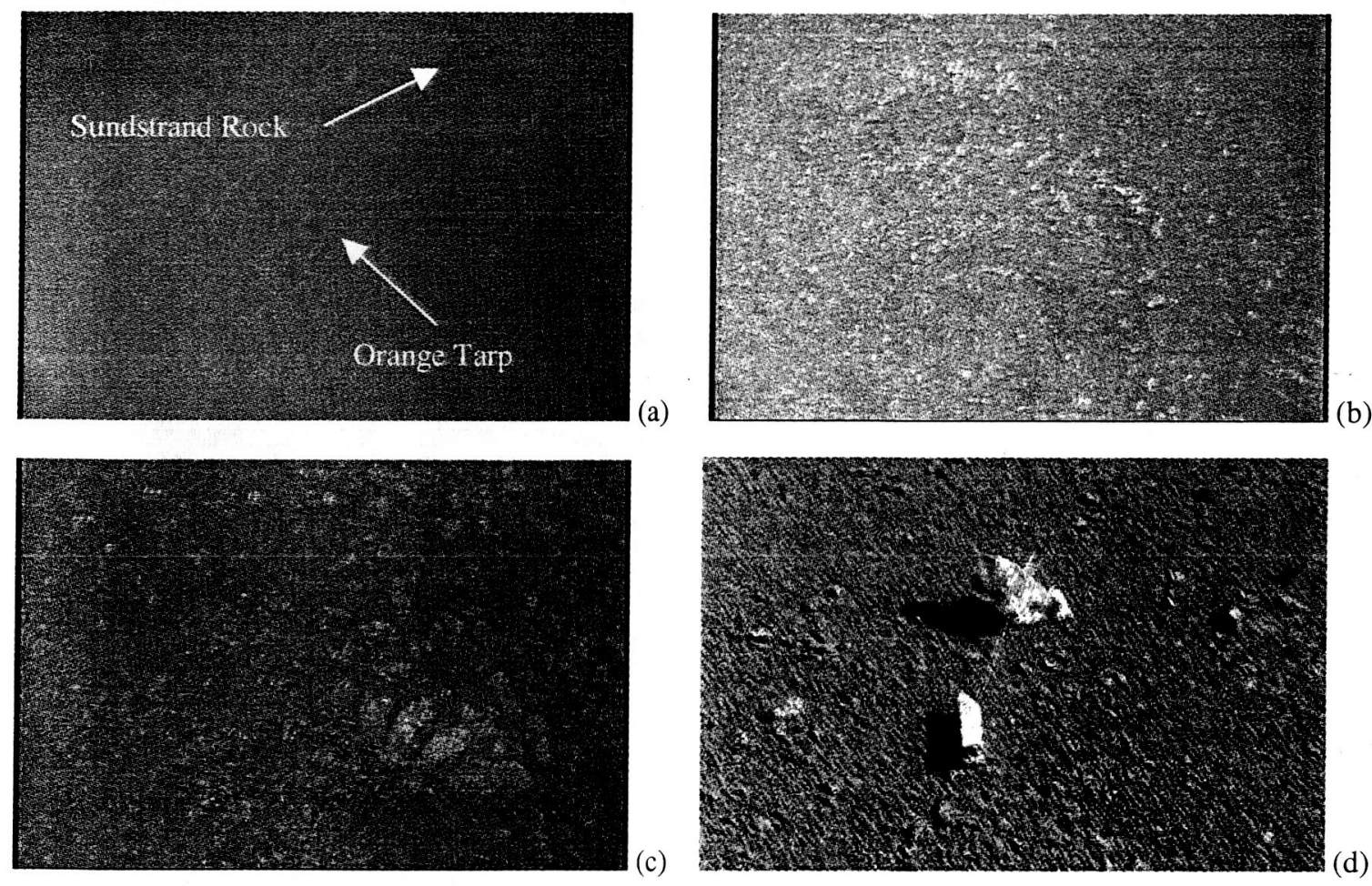

Fig 12. - Drop Probe: (a) UAV downward-pointing camera, (b) probe midway through descent, (c) close to contact with ground, and (d) probe on ground

Other approaches that might be taken to assess scale and overall context include: maneuvering the aircraft to gain a unique and improved view of a feature of interest, such as flying low and slow (Fig. 13), and flying over made-made artifacts (Fig. 14). Even for aerial explorers on Mars a case can be made to acquire aerial images of artifacts on the ground such as rovers and landers. 

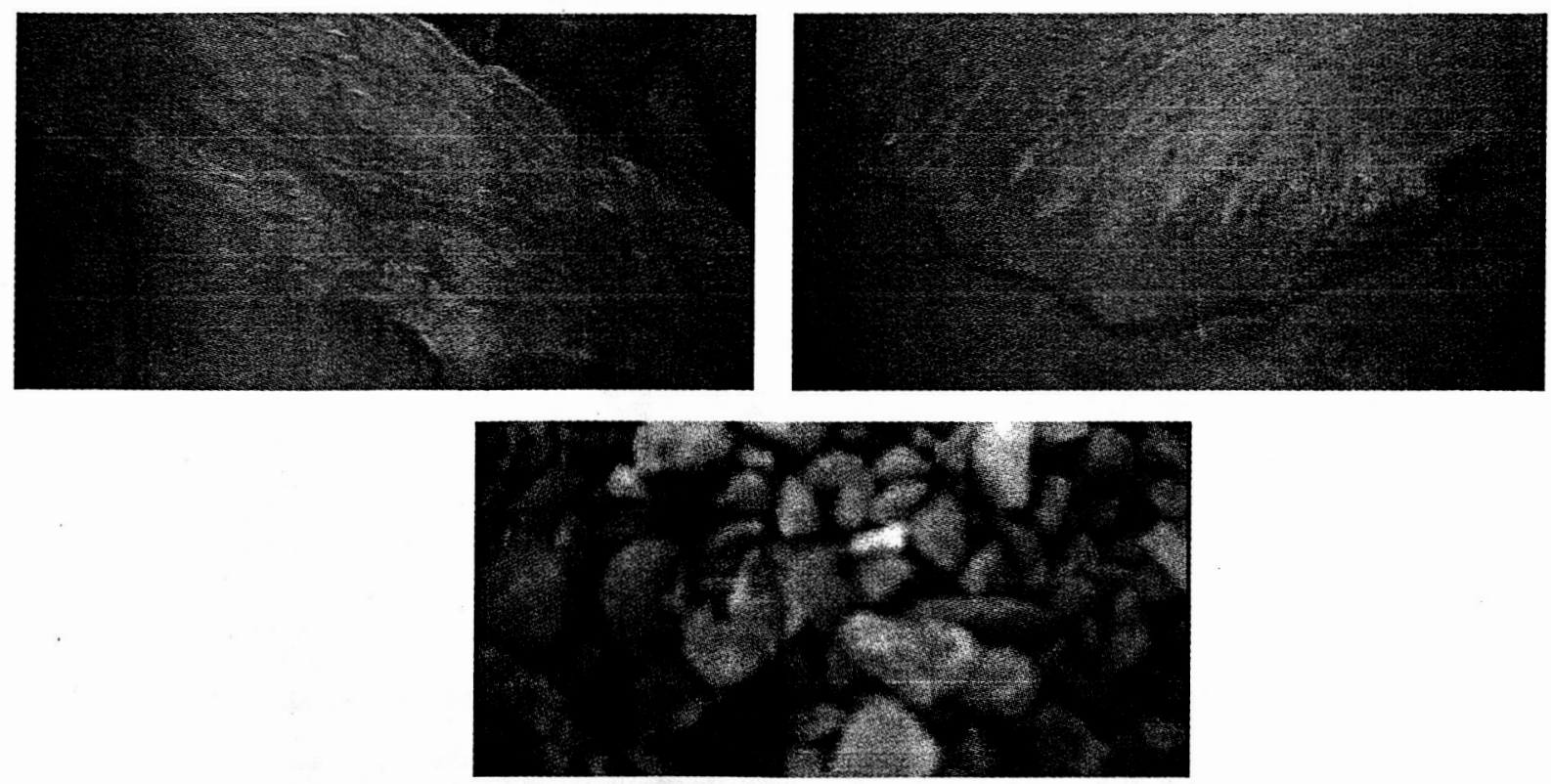

Figure 13. - Different scales and context as determined by progressively flying lower and slower over and landing on a dry riverbed
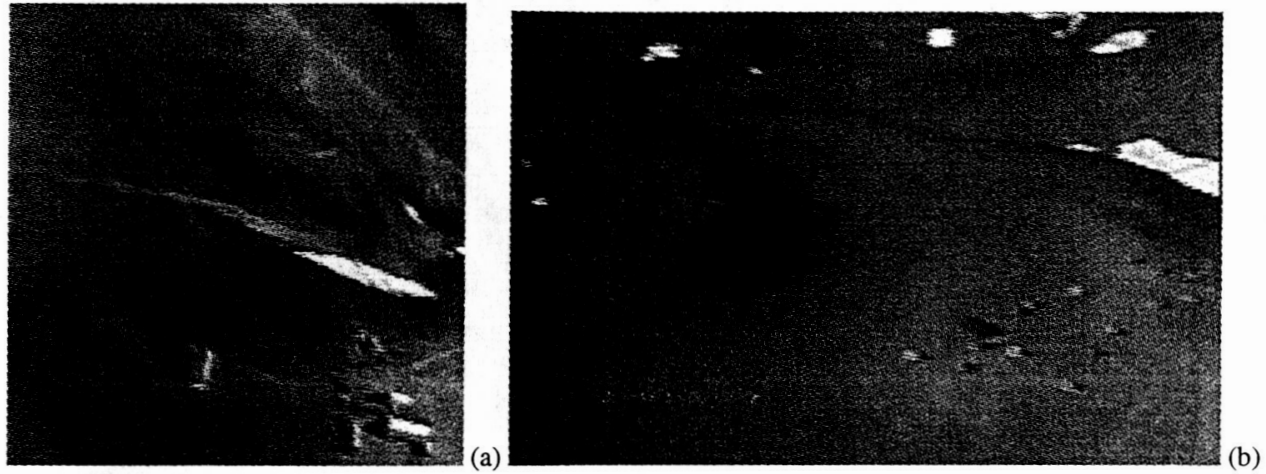

Figure 14. - (a) Haughton base camp with "Fortress" in background and (b) "tent city" with lee-side of Pete Conrad Valley in far background.

Landing is not an option for Mars aerial explorers. A "soft" crash where the data storage and telemetry devices survive is the best scenario to strive to achieve. All aerial explorers will ultimately come to ground, and a robust design that allows for data transmittal beyond the termination of flight should be a desirable goal. In that case, images such as Figure 13 should be anticipated and accounted for in mission planning.

\section{A QUESTION OF PERSPECTIVE}

In addition in providing improved resolution images of planetary surface terrain, as compared to satellite imagery, an aerial vehicle can also provide unique viewpoint perspectives of that terrain. Figure 15 illustrates a qualitative comparison of an aerial perspective of the "Fortress" rock formation near the Haughton Crater base camp versus ground images from all four quadrants of the same formation. The aerial images were taken with a $900 \mathrm{MHz}$ wireless downward-pointing video camera using a fisheye lens. Figure 16 is a compiled mosaic of aerial images from the same aerial video as shown in Fig. 15. Aerial imagery offers a balance of detail and overview that is unavailable from either space or ground. In many cases, the intermediate perspective may be the most valuable and well worth the use of a short lived asset such as a planetary aerial explorer. 


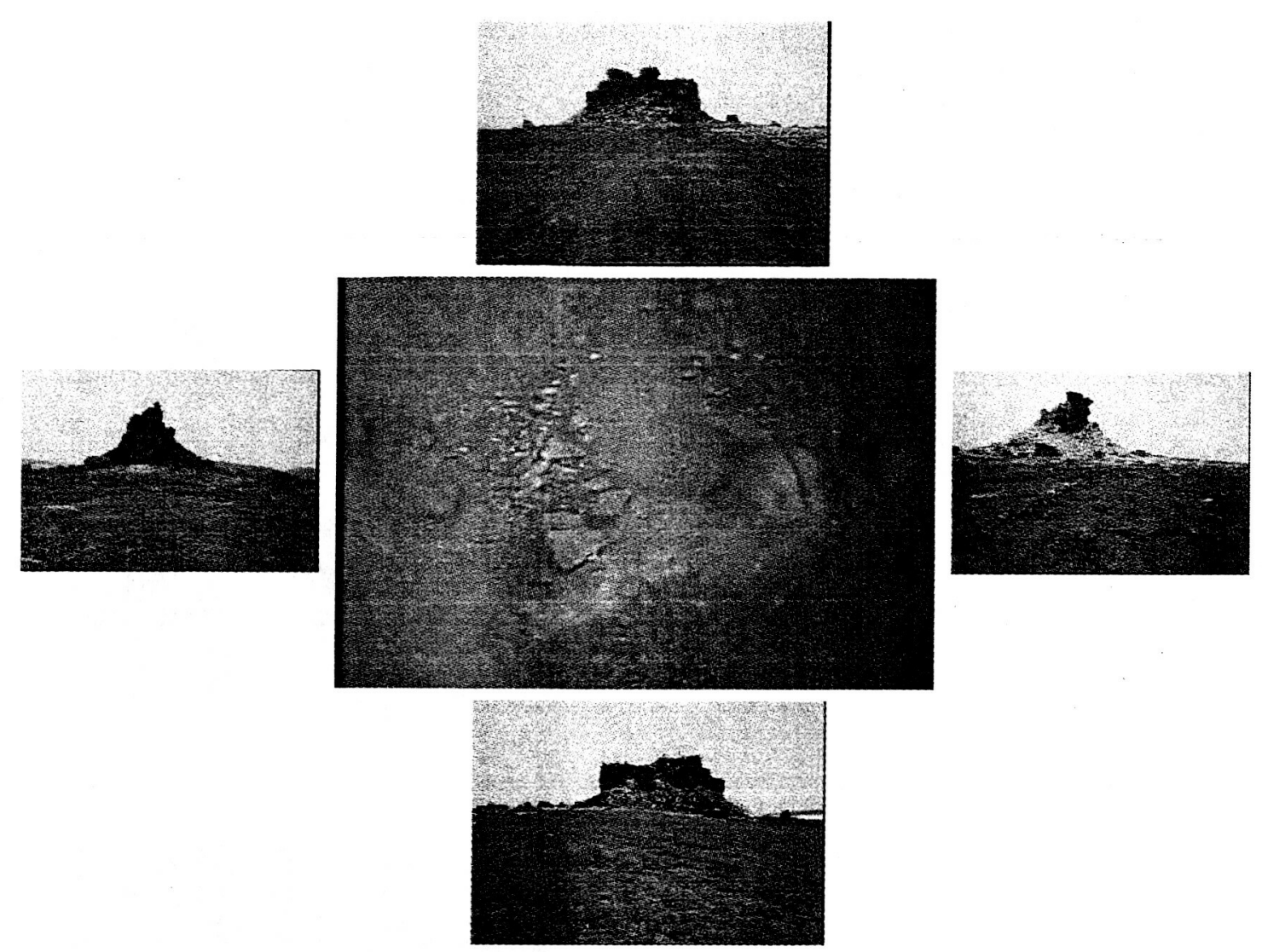

Figure 15. - Aerial perspective vs. images from the ground (all four quadrants); "Fortress" rock formation on Devon Island.

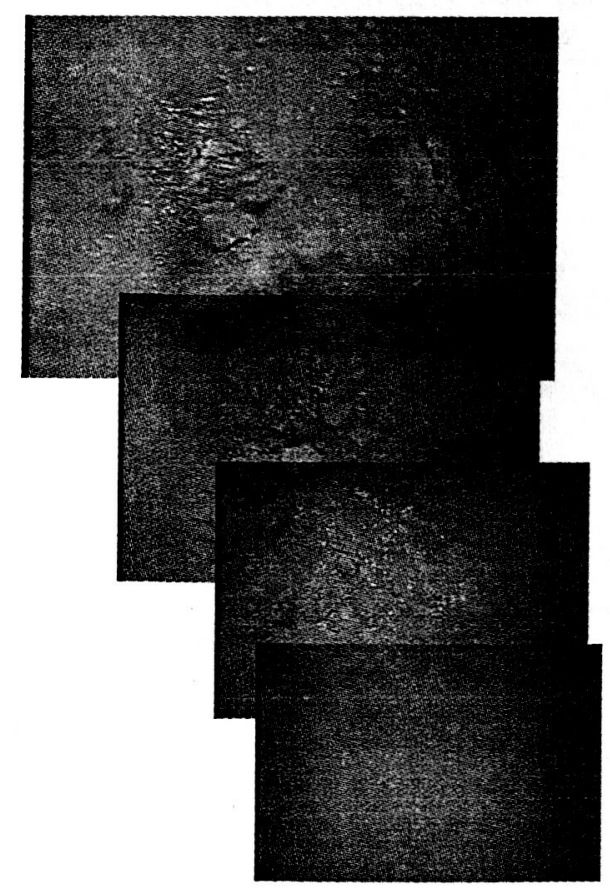

Figure 16. - Aerial image mosaic of Fortress rock.

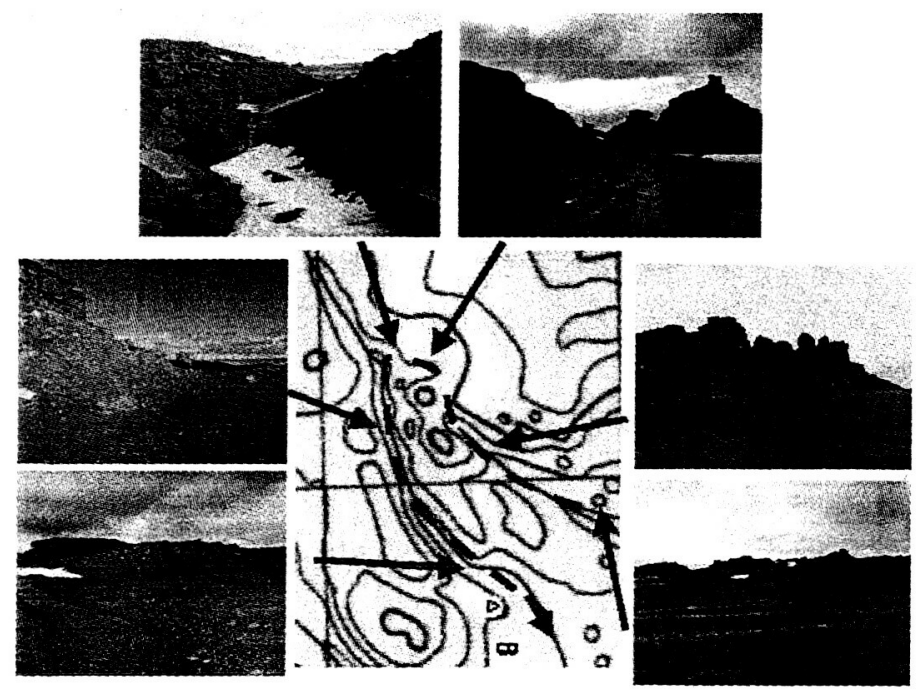

Figure 17. - Simulated rover trek through "Pete Conrad" Valley. 


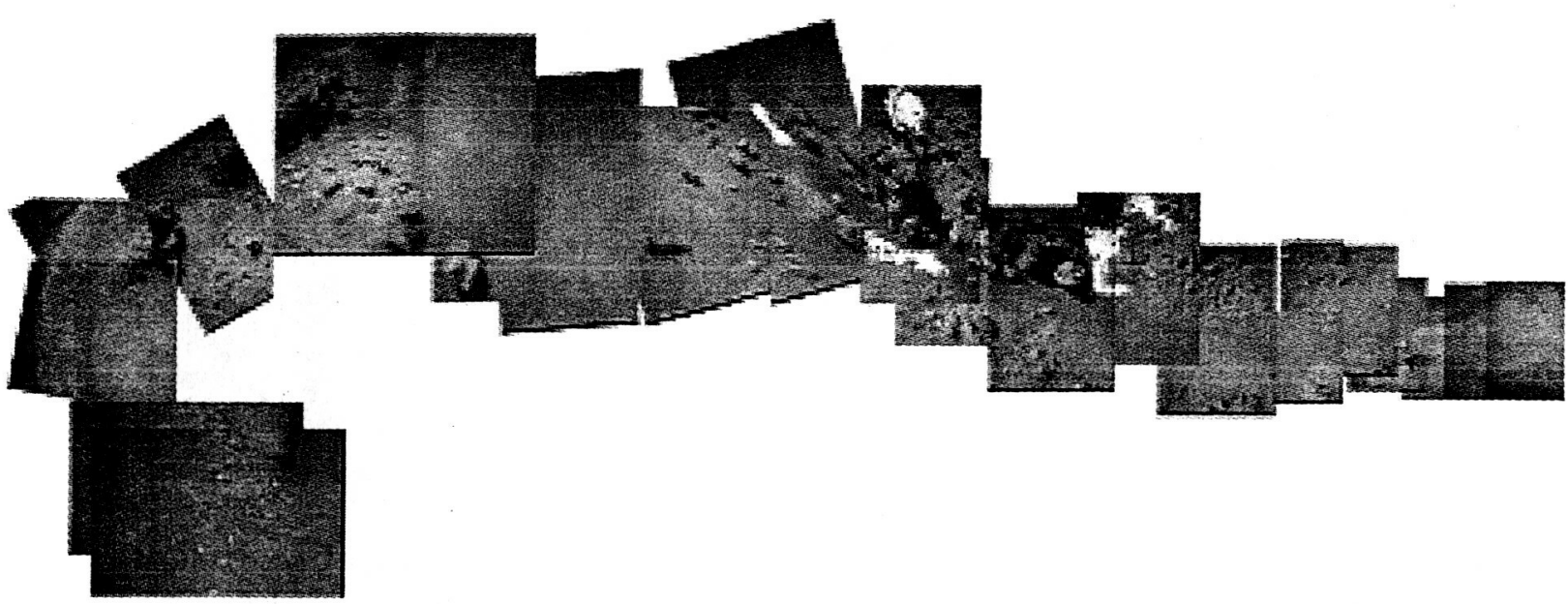

Figure 18. - Aerial image mosaic of a portion of Pete Conrad valley.

The fundamental assumption underlying all planetary aerial vehicle concepts is that they provide a unique and scientifically valuable perspective to planetary science as compared to imaging from rovers and landers. Figure 17 shows representative images for a simulated rover trek through Pete Conrad valley using a camera mounted on an All Terrain Vehicle (ATV). This was not an easy excursion for relatively inexperienced ATV riders, and would be difficult as well for rovers to traverse. As a counterpoint to the simulated rover perspective, Fig. 18 shows a mosaic composite of aerial images acquired by low-altitude, circling over-flights of the upper region of the Pete Conrad valley.

\section{A QUESTION OF BANDWIDTH}

Traveling at near-transonic speeds, at low to medium altitudes, an aerial explorer flying over the Martian landscape faces an extraordinary challenge in acquiring, processing, and evaluating (whether for navigation or scientific investigation) terrain imagery data. The small, fixed-wing UAVs flown during the Haughton field demonstrations are relatively low-speed aircraft (40-60 kts). Therefore, only a partial sense of the bandwidth issues related to a high-speed Mars airplane can be gained from the Haughton testing.

\section{AERIAL VEHICLE AUTONOMY}

Several BAT UAV flights were conducted on Devon Island. All flights used GPS waypoint navigation. Figure 19 is a representative flight plan for the BAT UAV. Figures 20 a-b though 24 a-b are a series of matching forward- and downward-pointing camera images for waypoints flown during one of the BAT UAV flights. 


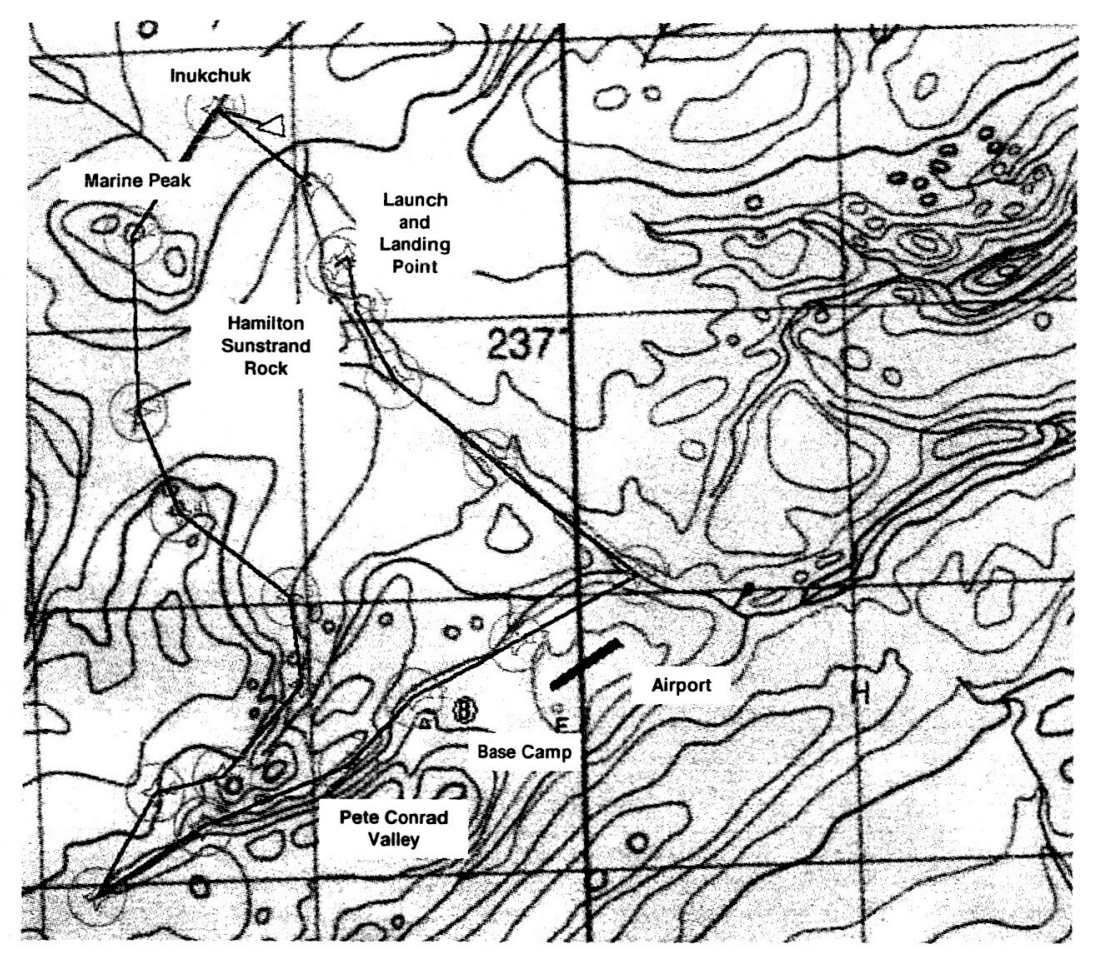

Figure 19. - Representative 2003 Field Season Aerial Survey Flight Plan
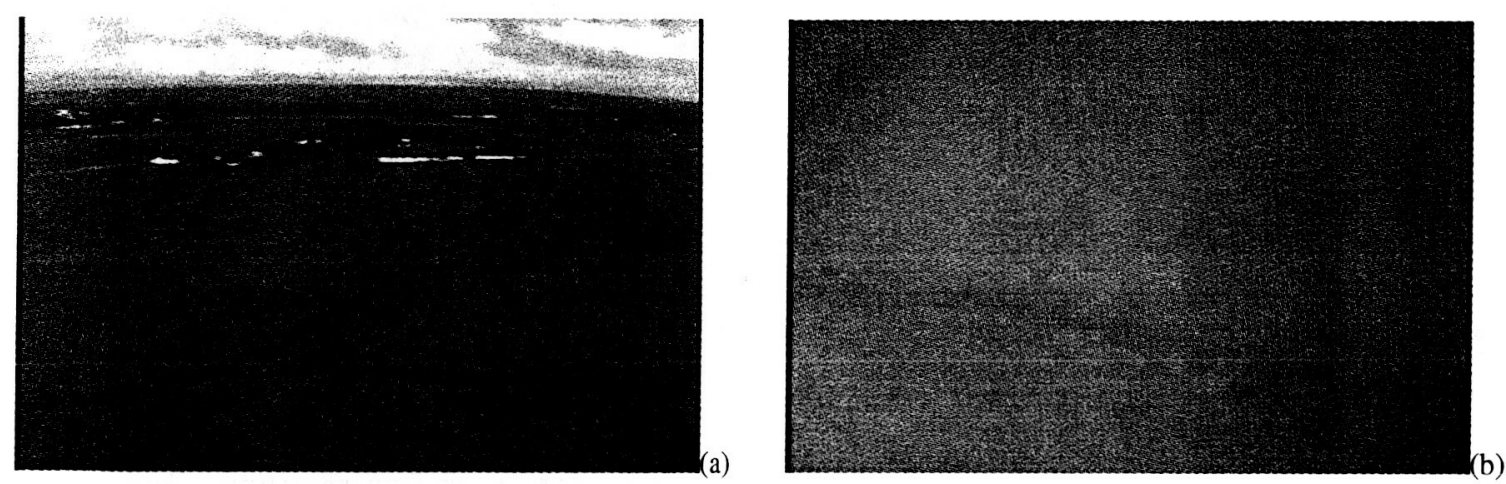

Figure 20. - BAT Aerial Explorer Skirting Along the Edges of the Von Braun Planitia - Waypoint \#1 (Seq. 100) (a) Forward (Horizon) Pointing Onboard Camera and (b) Downward Pointing
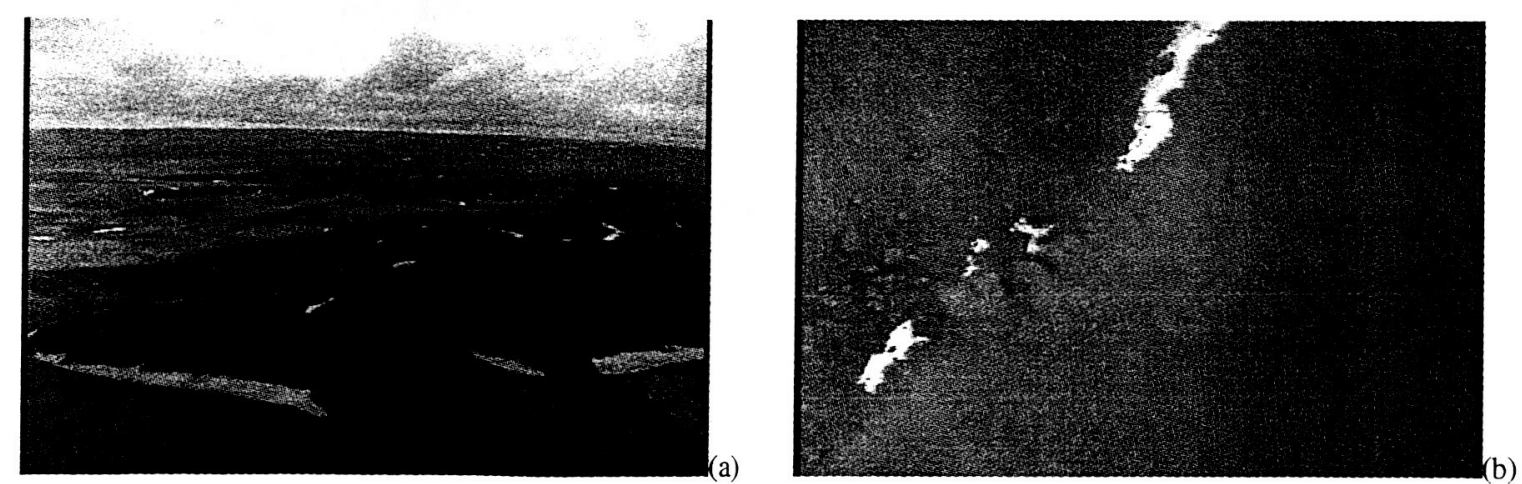

Figure 21. - Waypoint \# (Seq. 200) 

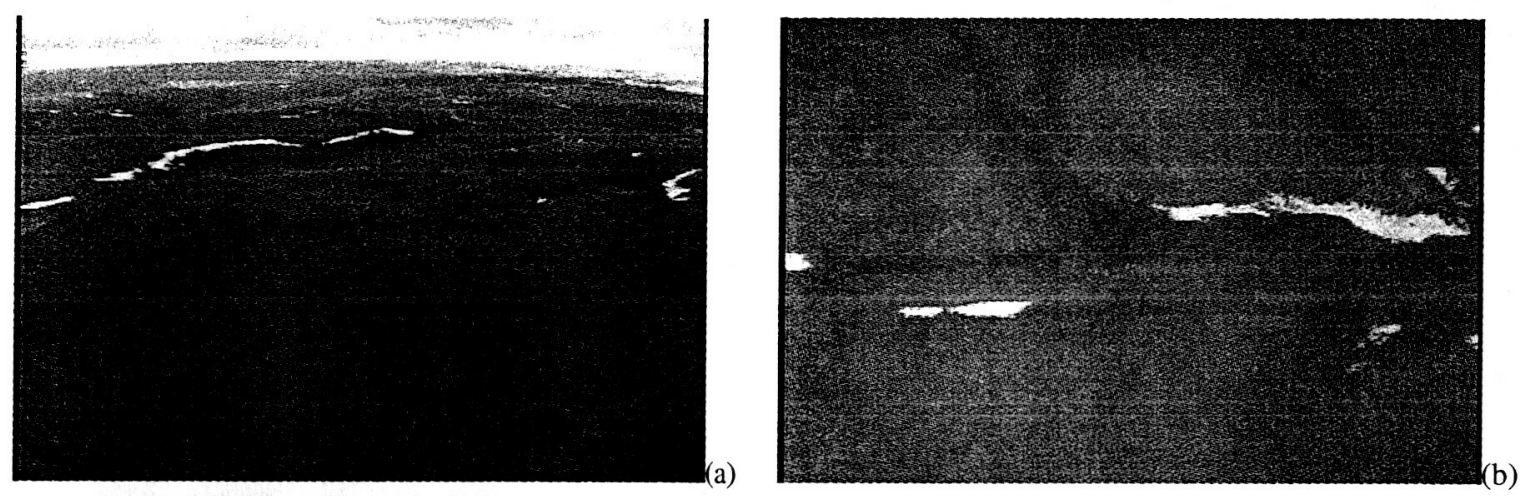

Figure 22. - Waypoint \# (Seq. 300)
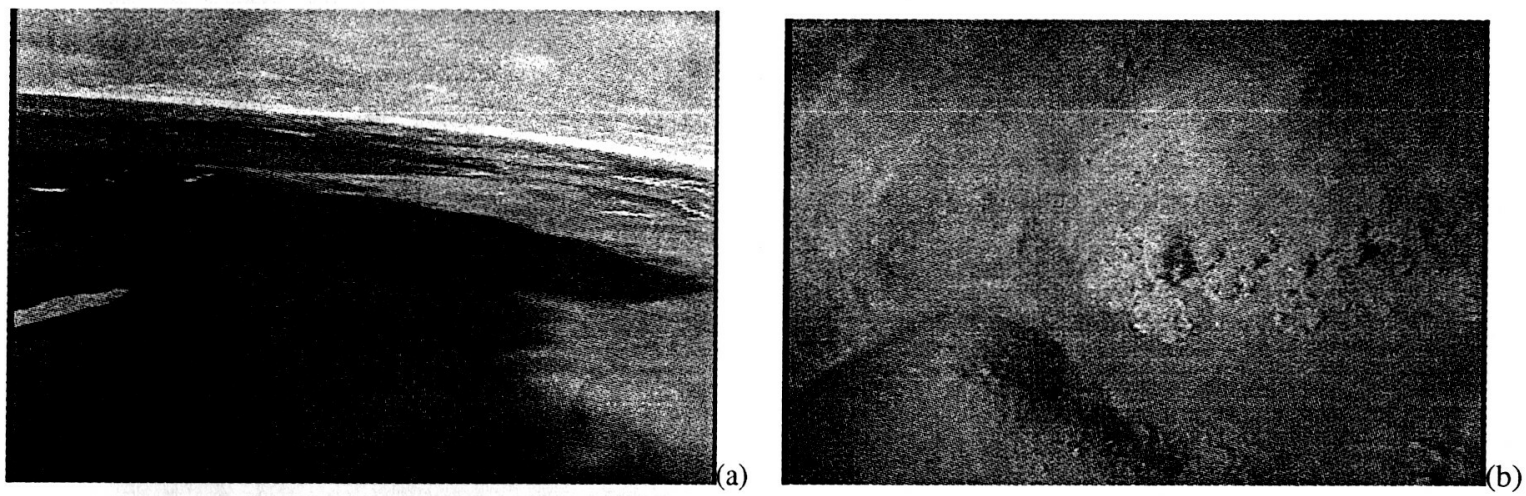

Figure 23. - Waypoint \# (Seq. 400)
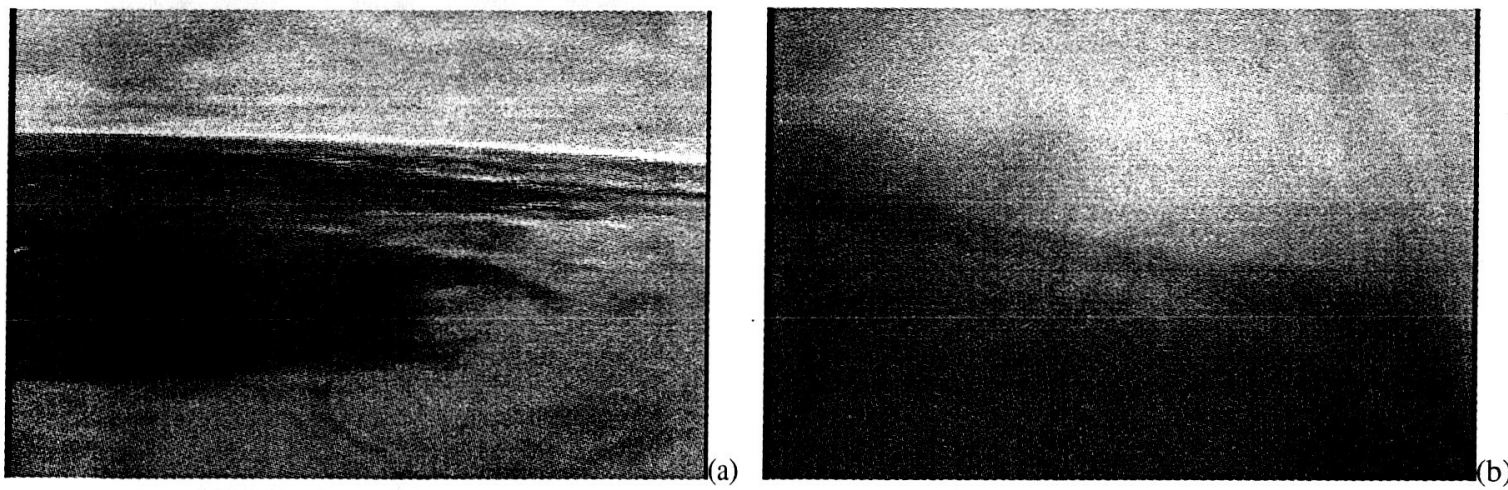

Figure 24. - Waypoint \# (Seq. 500)

\section{NAVIGATION VERSUS INVESTIGATION}

As in surface rovers, the array of imaging sensors onboard aerial explorers will need to play dual roles as navigation aids as well as essential science investigation tools. To arrive at an optimum-imaging suite is no easy task. Table 4. contrasts the relative advantages and disadvantages of airborne cameras and maneuvers strategies. 
Table 4 - Qualitative Assessment of Camera Pointing \& Maneuvers on Imagery Objectives

\begin{tabular}{|c|c|c|}
\hline & Advantages & Disadvantages \\
\hline \multicolumn{3}{|l|}{ Camera Pointing } \\
\hline Forward-pointing & $\begin{array}{l}\text { Good situational awareness. Good for visual } \\
\text { navigation. }\end{array}$ & Not as good for high-quality science imagery. \\
\hline $30-45$ deg. forward & Good compromise camera position. & $\begin{array}{l}\text { Perhaps too much of a compromise for detailed analysis of terrain; } \\
\text { significant post-processing is required to transform images to a } \\
\text { mosaic map of the planetary surface. }\end{array}$ \\
\hline Downward-pointing & Good for high-quality science imagery & Poor situational awareness and not as good for visual navigation. \\
\hline Pan/tilt/zoom & $\begin{array}{l}\text { Potentially use fewer cameras, or lower } \\
\text { maneuvering flight-path deviations, for the } \\
\text { same imaging coverage. Can acquire off-axis } \\
\text { (lateral) images while maintaining straight and } \\
\text { level flight. }\end{array}$ & $\begin{array}{l}\text { Continue to examine trades between number and position of fixed } \\
\text { cameras (with a need for intelligent switching between them) versus } \\
\text { fewer cameras with more advanced capabilities such as pan, tilt and } \\
\text { zoom, but perhaps subjective to increased concern about risk, } \\
\text { reliability and control complexity. }\end{array}$ \\
\hline \multicolumn{3}{|l|}{ Maneuvers } \\
\hline Circling & $\begin{array}{l}\text { Found to provide considerable insight into } \\
\text { discrete terrain features of interest such as } \\
\text { rock formations. Sequential images from } \\
\text { successive over flights can allow accurate } \\
\text { three-dimensional feature extraction. }\end{array}$ & $\begin{array}{l}\text { Energy and time intensive. Has to be a priority, high-value terrain } \\
\text { feature of interest to justify performing, particularly for planetary } \\
\text { aerial explorers. }\end{array}$ \\
\hline $\begin{array}{l}\text { Tight banking turns } \\
\text { or shallow rolls }\end{array}$ & $\begin{array}{l}\text { Time efficient means to acquire horizon } \\
\text { images from downward pointing cameras, } \\
\text { allowing for a partial panoramic view of the } \\
\text { immediate area. Also allows imaging tall or } \\
\text { steep surfaces such as canyon walls and cliff } \\
\text { faces. }\end{array}$ & Energy intensive. \\
\hline Zigzags & $\begin{array}{l}\text { Puts to the test assumptions about the terrain } \\
\text { being flown over; i.e. by performing periodic } \\
\text { zigzags, in otherwise straight and level flight } \\
\text { paths, downward pointing cameras can } \\
\text { validate whether or not something of interest } \\
\text { lies just off the main flight path. }\end{array}$ & $\begin{array}{l}\text { Somewhat energy and time intensive. Conditional logic on when, } \\
\text { and when not to, perform zigzags and other maneuvers may be } \\
\text { computationally complex or intensive. }\end{array}$ \\
\hline Low and slow & $\begin{array}{l}\text { Could be an efficient means of coupling } \\
\text { energy management with bio-inspired search } \\
\text { and find strategies } 2,4 \text {. }\end{array}$ & $\begin{array}{l}\text { Limitations, because of high stall speed, on how low and slow a Mars } \\
\text { flyer might be able to go. This problem is compounded if minimal } \\
\text { advanced data is available for terrain being over flown. In that case, } \\
\text { there could be increased flight safety risk. }\end{array}$ \\
\hline Follow borders & $\begin{array}{l}\text { Efficient search and find strategy; e.g. rather } \\
\text { than flying over the barren plain, focus on the } \\
\text { geologically and biologically more interesting } \\
\text { outskirts. }\end{array}$ & $\begin{array}{l}\text { Could be very energy and time intensive if the border is ill defined or } \\
\text { circuitous in nature. }\end{array}$ \\
\hline
\end{tabular}

\subsection{Lessons Learned: Positive}

Flight tests at the Devon Island Mars-analog site provided many important lessons learned. In the positive, even though still in the earliest stages of development, the power of aerial robotic field assistants to empower terrestrial field scientists (and ultimately planetary scientists) could clearly be seen from the Haughton demonstrations. The end result of such preliminary work could well be a close working partnership between aerial robots and scientists.

\subsection{Lessons Learned: Challenges}

First, it was clear from the UAV flight tests during the Haughton field seasons that visibility and weather conditions can have a large impact on aerial survey productivity. (Fog, rain, hail, and snow all occurred during the Arctic summer.) Adverse local conditions could also be a problem on Mars where suspended dust particulates in the atmosphere (let alone dust storms) could have a severe detrimental effect on aerial surveys. Second, radio interference with wireless video feed from the UAV was still a significant issue at Devon Island (from the electronics and telecom at Base Camp, which lay close to the farthest corner of the Von Braun Planitia circumnavigation). Third, the image quality of the two low-cost wireless video cameras onboard the UAV wasn't as good as desired. Other approaches to arrive at improved imagery data need to be developed or acquired. 


\section{DERIVING INSPIRATION FROM BIOLOGY}

The natural world is a rich source of problem-solving approaches. Like many other aerospace applications, aerial explorers can benefit from bio-inspired technologies. In particular, a considerable amount of emphasis has been placed on examining bio-inspired mission scenarios, flight "behaviors," and decision-making during search-and-find missions. The IAV project has had strong complementary research ties with the "BEES (Bio-inspired Engineering for Exploration Systems) for Mars" project ${ }^{5-6}$. Aerial imagery and telemetry data from the Haughton 2002 field season is currently being used to develop and refine a bio-inspired vision-system based upon a cellular neural-network (CNN) semiconductor device and Adaptive Resonance Theory (ART) firmware ${ }^{6}$.

The IAV project's BAT UAV has been augmented with a PC-104 "mission computer" to complement the COTS "flight computer" and avionics. This will allow the implementation of several different bio-inspired vehicle autonomy search and find strategies. The 2003 Haughton field season afforded the IAV project an opportunity to simulate some of these search and find strategies using the COTS BAT UAV system and a network of ground-based laptop computers.

\section{FUTURE WORK}

The lessons learned from the imaging work on Devon Island in field seasons 2002 and 2003 will be crucial for preparing for a fully mission-representative set of flights in the future. In addition to the forward- and downwardpointing cameras employed to date, the BAT UAV will be augmented with a video camera having both zoom and pantilt.

Goals for future testing other Mars-analog sites should focus on the following:

A. Coordinated imagery fusion: wireless video from a radio controlled aircraft relayed through BAT (or vice versa), or alternatively through relays on ATV's (acting as rover surrogates). Vision software augmented such that trainer aircraft or ATV camera feed can be used to spot tarps for BAT.

B. Perform a quantitative assessment of various search and find strategies by seeding multiple targets of interest or differing search areas. This should hopefully support quantifiable statements such as 3 of 4 targets identified within rough terrain search area, in a fifteen-minute search, with a given strategy.)

C. Coordinate with a field astrobiologist to augment his or her field work with the BAT and other assets. (For example, detailed mosaic mapping of rock formation faces for context.)

D. Support a 1-2 day scientific trek with the BAT, performing aerial surveys at each key stopping point. The production of aerial image mosaics would be a key deliverable to trek organizers.

E. Distributed sensor work (multiple drop pods, different types, and locations) and tailored emplacement of sensors (hillsides, canyons, or valley walls). Look at ground penetrators, and "tether-bots" (Fig. 25).
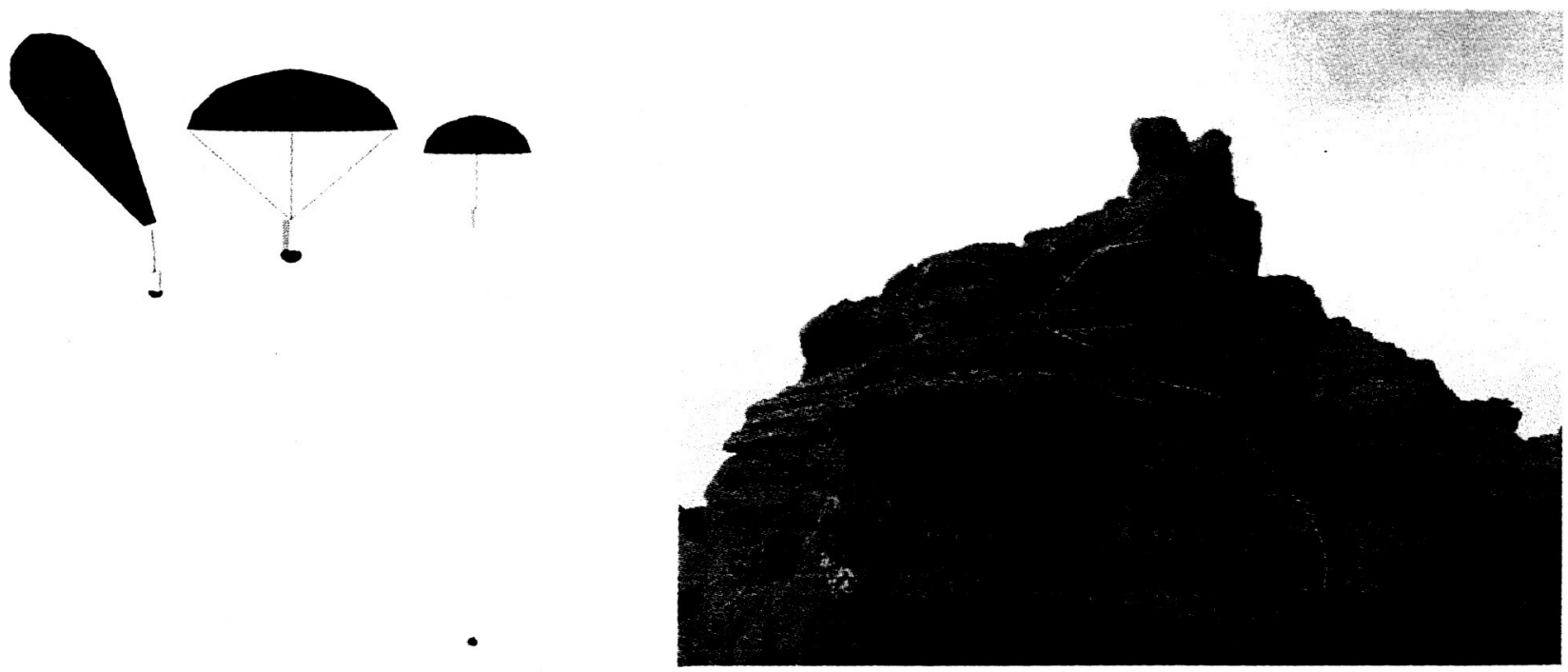

Figure 25. - Notional deployment and operation of a Tetherbot concept. 
Ultimately the goal of the IAV project is to transition the technologies developed to other NASA programs - both planetary and terrestrial science missions.

\section{CONCLUDING REMARKS}

Many issues related to successfully acquiring aerial imaging data of a type and quality required for scientifically valuable investigations for planetary science missions were discussed in this paper.

There is considerable electronic imaging research and development work that lies ahead in order to elevate the future development of robotic planetary aerial explorers from merely technological and engineering triumphs to profound instruments of scientific discovery. The initial efforts discussed within this paper will hopefully help begin to address this critical technical area.

\section{ACKNOWLEDGMENTS}

This work was funded by the NASA Computing, Information, and Communication Technology (CICT) -- Intelligent Systems element -- program, managed by Dr. Butler Hine, of NASA Ames Research Center. The programmatic contributions of Dr. Steven Zornetzer, NASA Ames Acting Deputy Director, and Edwin Aiken of the Army/NASA Rotorcraft Division at Ames Research Center are also gratefully acknowledged. The technical expertise of Mr. Ray Demblewski is also acknowledged. Finally, the contributions of the technical staff of MicroPilot, Inc. and MLB, Inc. were crucial to the successful conduct of the research in this paper and their efforts are gratefully acknowledged.

\section{REFERENCES}

[1] Lee, P., "Mars on Earth: The NASA Haughton-Mars Project," Ad Astra: The Magazine of the National Space Society, Volume 14, Number 3, May/June 2002.

[2] Plice, L., Pisanich, G., Lau, B., and Young, L., "Biologically Inspired 'Behavioral' Strategies for Planning and Execution of Missions Using General Classes of Aerial Explorers", 2003 IEEE Aerospace Conference, Big Sky, MT, March 8-15, 2003.

[3] Plice, L., "Robot Economy," Robosphere 2002: Workshop on Self-Sustaining Robotic Ecologies, NASA Ames Research Center, Moffett Field, CA, November 14-15, 2002.

[4] Pisanich, G., Ippolito, C., Plice, L, Young, L., and Lau, B., "Actions, Observations, and Decision-Making: Biologically Inspired Strategies for Autonomous Aerial Vehicles," To be presented at the AIAA Aerospace Sciences Conference, Reno, NV, January 2004.

[5] S. Thakoor, "Bio-Inspired Engineering of Exploration Systems", Journal of Space Mission Architecture, Issue 2, Fall 2000, p 49-79.

[6] S. Thakoor, J. Chahl, M.V. Srinivasan, F. Werblin, L.Young, B. Hine, S. Zornetzer "Bio-inspired Engineering of Exploration Systems for NASA and DoD”, Artificial Life Journal, 2002, Vol 8, Issue 4, pages 357-369. 